Ana Paula Lopes dos Santos

Francisco Antonio de Castro Lacaz ${ }^{2}$

${ }^{1}$ Departamento de Psicologia do Instituto de Ciências Humanas e Filosofia da Universidade Federal Fluminense. Rio de Janeiro, RJ, Brasil.

${ }^{2}$ Departamento de Medicina Preventiva da Escola Paulista de Medicina da Universidade Federal de São Paulo. São Paulo, SP, Brasil.

Contato:

Ana Paula Lopes dos Santos

E-mail:

anapaulalopes.uff@gmail.com

Trabalho baseado na tese de Doutorado de Ana Paula Lopes dos Santos intitulada Tecendo redes, superando desafios: estudos dos processos de trabalho de casos exitosos em Saúde do Trabalhador no Sistema Único de Saúde do Estado de São Paulo, defendida em 2010, na Universidade Federal de São Paulo.

Financiamento: Ana Paula Lopes dos Santos contou com bolsa de doutorado da Capes.

Os autores declaram não haver conflitos de interesse.

\section{Ações de vigilância em saúde do trabalhador e ambiente: análise da atuação do Centro de Referência em Saúde do Trabalhador de Campinas em postos de combustível}

Surveillance actions in worker's health and environment: analyses of the procedure carried out in gas stations by the Campinas Worker's Health Reference Center, Campinas, SP, Brazil

\title{
Resumo
}

Frente às mudanças no mundo do trabalho contemporâneo e suas repercussões sobre a saúde e o ambiente, novos desafios se impõem à Atenção Integral à Saúde do Trabalhador no Sistema Único de Saúde. Com o objetivo de analisar as experiências neste campo, estudamos o Projeto de Vigilância dos Postos de Combustível do Centro de Referência em Saúde do Trabalhador de Campinas/ SP. A partir de entrevistas com profissionais de saúde e outros atores envolvidos no projeto, reconstruímos seu percurso, avaliando potencialidades e dificuldades enfrentadas. Observamos que a construção coletiva das ações e a formação de agentes para a realização da vigilância nos postos de combustível articulou profissionais de diversas formações, especialidades e de diferentes instituições. Para os entrevistados, tal processo ampliou o olhar dos envolvidos sobre a exposição ao risco químico e uniu esforços, repercutindo na melhoria das condições de trabalho, no aumento do controle social e na regulamentação das formas de produção, distribuição e consumo dos combustíveis. As dificuldades apontadas consistem naquelas relativas ao trabalho em grupos, ao que se alia a sobrecarga de trabalho. Concluímos que a definição de ações prioritárias que visem à formação de redes intra e intersetoriais é estratégica para modificar de forma positiva os processos de trabalho em prol da saúde e ambiente.

Palavras-chave: saúde do trabalhador; saúde ambiental; Sistema Único de Saúde; vigilância em saúde do trabalhador; postos de combustível.

\begin{abstract}
Due to the changes in the contemporary labor world and their repercussions on health and environment, new challenges are posed to Worker's health Integrated Care from the Brazilian National Unified Health System. Aiming at analyzing the experiences in this field, we examined the Surveillance Project carried out in Gas Stations by the Worker's Health Reference Center of Campinas, São Paulo. Based on interviews with health workers and other actors involved, we reconstructed its trajectory estimating its potentialities and difficulties. We observed that the collective construction of actions and the preparation of the agents to conduct surveillance in gas stations joined professionals from different institutions, with distinct backgrounds and expertise. In the interviewees' opinion, the process improved the involved agents' view concerning exposure to chemical risk, and gathered efforts which resulted in improving working conditions, and enlarging social control, besides regulating the gas production, distribution and consumption. They mentioned difficulties related to group work added to overload of work. We concluded that establishing priorities aimed at developing intra and inter-sector networks is strategic to change working processes in such a way that it benefits health and environment.
\end{abstract}

Keywords: worker's health; environmental health; Brazilian Unified Health System; worker's health surveillance; gas stations. 


\section{Introdução}

Vigilância em Saúde do Trabalhador e Ambiente: um
desafio para o Sistema Único de Saúde (SUS)

Com o avanço da globalização capitalista, as relações entre trabalho, saúde e ambiente se complexificam:

A crise ambiental global tem obrigado todos os setores da sociedade a rever conceitos e valores, explicitando conflitos de interesse e evidenciando a insustentabilidade do modelo de desenvolvimento. (BARCELLOS; QUITÉRIO, 2006, p. 171)

Com a crise, configura-se um mecanismo de exportação dos riscos para os países subdesenvolvidos, temática apontada por autores estrangeiros desde os anos 1980 (BAGNARA; BIOCCA; MAZZONIS, 1981; CASTLEMAN, 1983) e que passou a ser apropriada por autores brasileiros (RIGOTTO, 2003; RIGOTTO; AUGUSTO, 2007). No que tange, por exemplo, aos produtos químicos produzidos, as inovações tecnológicas têm colocado no mercado entre 1.000 e 2.000 novas substâncias por ano, em uma velocidade muito maior do que a capacidade científica e institucional de analisá-las (PORTO; FREITAS, 1997). Com isso, as enormes quantidades de produtos químicos disponíveis:

[...] têm resultado em níveis de poluição em escala tal que vem alterando a composição química das águas, do solo, da atmosfera e dos sistemas biológicos do planeta, colocando em risco não só o bem estar, mas também a sobrevivência do planeta. (FREITAS et al., 2002, p. 251)

Da mesma forma, no Brasil, o crescimento dos problemas relacionados à segurança química ocorreu em proporção muito maior à capacidade que o Estado tem apresentado de enfrentá-los. A utilização indiscriminada dos recursos naturais e sua contaminação em função da coexistência de modos de produção arcaicos e modernos resultaram em diferentes formas e níveis da poluição química, o que impõe a necessidade de intervir sobre velhos e novos problemas (BARCELLOS; QUITÉRIO, 2006).

Historicamente, em âmbito nacional, a questão ambiental, no que tange à saúde, esteve vinculada ao saneamento básico e ao tratamento da água. Na década de 1970, em São Paulo e no Rio de Janeiro, são criadas, respectivamente, a Companhia Estadual de Tecnologia em Saneamento Ambiental (Cetesb) e a Fundação Estadual de Engenharia do Meio Ambiente (FEEMA), sem qualquer vínculo com o sistema de saúde (TAMBELLINI; CÂMARA, 1998). No entanto, a partir da década de 1980, diante do surgimento do campo Saúde do Trabalhador (ST), a relação entre produção, saúde e ambiente (LACAZ, 1996) fica cada vez mais perceptível, o que se articula, na década de
1990, com as preocupações advindas da Conferência das Nações Unidas sobre Meio Ambiente e Desenvolvimento (TAMBELLINI; CÂMARA, 1998). Nesse sentido, a incorporação da Vigilância Ambiental em Saúde é recente (BARCELLOS; QUITÉRIO, 2006), sendo conceituada como:

\begin{abstract}
[...] um conjunto de ações que proporcionam o conhecimento e a detecção de qualquer mudança nos fatores determinantes e condicionantes do meio ambiente que interferem na saúde humana, com a finalidade de recomendar e adotar as medidas de prevenção e controle dos fatores de riscos e das doenças ou agravos, em especial as relativas a vetores, reservatórios e hospedeiros, animais peçonhentos, qualidade da água para consumo humano, contaminantes ambientais, desastres naturais, acidentes com produtos perigosos, saneamento básico, disposição de dejetos humanos e animais e condições habitacionais. (BRASIL, 2002, p. 18-19)
\end{abstract}

Para orientar tais ações sobre o ambiente, Rigotto (2003) aponta a importância de estudos e pesquisas visando à avaliação de riscos, à implantação de programas de monitoramento ambiental pelas autoridades, à construção do aparato legal e institucional, tendo, como premissa norteadora, a interface entre ST e Saúde Ambiental (SA), que se configura como um caminho promissor, visto que ambas:

[...] podem se nutrir de uma mesma cosmovisão, de um olhar abrangente que contemple estas férteis e complexas inter-relações, para com ele iluminar a pesquisa, a formação dos profissionais, as políticas públicas e a ação política da sociedade. (RIGOTTO, 2003, p. 400)

O sucesso desse empreendimento depende de pesquisadores dispostos ao diálogo, competentes em suas áreas e com marcos referenciais teóricos e metodológicos construídos e compartilhados em grupo (PORTO; ALMEIDA, 2002), e essa aproximação de diálogos, ações, atuações e visões pode ser favorecida pelo conceito de Vigilância em Saúde do Trabalhador (Visat).

A Visat se constitui como uma prática interinstitucional e interdisciplinar na perspectiva da construção de processos articulados de intervenção sobre os processos de trabalho na relação com a saúde (MACHADO, 2005a) e contempla a integralidade das ações na organização dos serviços por meio do trabalho em equipe multiprofissional e da relação complementar de vários serviços (SPEDO, 1998). De acordo com Machado (1996), o caráter interinstitucional, interdisciplinar e de integralidade de ações é alcançado de duas formas. A primeira inclui como fundamental a efetiva participação dos trabalhadores na definição de prioridades, na preparação das inspeções sanitárias, na definição de propostas e na análise e avaliação dos resultados como forma de controle social, transparência institucional, garantia de qualidade e implementação 
das propostas fundamentadas na incorporação do saber e força política dos trabalhadores. A segunda ressalta as necessárias articulações entre academia, órgãos de vigilância, outros órgãos relacionados à saúde dos trabalhadores (como Instituto Nacional do Seguro Social - INSS, Fundação Jorge Duprat Figueiredo de Segurança e Medicina do Trabalho - Fundacentro, Superintendências Regionais do Trabalho e Emprego - SRTE), empresas, representações de trabalhadores (sindicatos), assim como as relações estabelecidas entre os órgãos dos Poderes Executivo, Legislativo e Judiciário. A relação das investigações com processos de tomada de decisão no nível das empresas e do poder executivo depende da forma e da força com que se estabelecem tais articulações (SPEDO, 1998).

Tais abordagens foram incorporadas em algumas experiências nos serviços de saúde e institucionalizadas pela Instrução Normativa de Vigilância em Saúde do Trabalhador, conforme Portaria MS/GM no 3.120 de 01/07/98 (BRASIL, 1998). Nela, a atividade de Visat implica na superação dos limites conceituais e institucionais das ações dissociadas de vigilância epidemiológica e sanitária, sendo conceituada como:

[...] uma atuação contínua e sistemática ao longo do tempo, no sentido de detectar, conhecer, pesquisar e analisar os fatores determinantes e condicionantes dos agravos à saúde relacionados aos processos e ambientes de trabalho, em seus aspectos tecnológico, social, organizacional e epidemiológico, com a finalidade de planejar, executar e avaliar intervenções sobre esses aspectos, de forma a eliminá-los ou controlá-los. (BRASIL, 1998)

A implantação das ações de Visat resulta em uma diversidade de experiências que tem como elemento comum "[...] um processo de articulação de ações de controle sanitário no sentido de promoção, proteção e atenção à saúde dos trabalhadores" (MACHADO, 1997, p. 34). Apesar das dificuldades colocadas, influências da prática cotidiana de Visat, desenvolvidas pelos Centros de Referência em Saúde do Trabalhador (CRST), trouxeram uma mudança no perfil e na magnitude das estatísticas de certas doenças profissionais no Brasil, como o benzenismo em trabalhadores siderúrgicos na década de 1980 e as Lesões por Esforços Repetitivos (LER) na década de 1990 (MACHADO, 1996; LACAZ, 1996). Além disso, tais experiências incorporaram denúncias de trabalhadores e casos graves de acidentes e doenças como eventos sentinelas deflagradores de ações nos ambientes de trabalho (LACAZ, 1996).

Frente a essas mudanças que se configuram no mundo do trabalho contemporâneo e a suas repercussões sobre a saúde e o ambiente, faz-se necessária a discussão dos rumos das ações no âmbito do
SUS, visto ser nesse cenário de turbulência que os CRSTs constroem suas práticas (DIAS et al., 2008). O desenvolvimento de ações em ST que priorizem a intra e a intersetorialidade é considerado estratégico para superar as dificuldades e somar forças no sentido de modificar positivamente os processos de trabalho em prol da saúde e ambiente. Em relação à questão da segurança química, no plano da intervenção, é necessário agregar ações do Sistema Único de Saúde (SUS) em uma atuação integrada e interinstitucional entre o Ministério da Saúde, do Meio Ambiente, da Previdência Social, do Trabalho e Emprego, dentre outros (TAMBELLINI; CÂMARA, 1998; VASCONCELLOS, 2007). Desse modo:

\begin{abstract}
Trabalhar integradamente as questões relacionadas à Saúde do Trabalhador e ao Meio-ambiente é um passo fundamental para se desenvolver novas abordagens teórico-metodológicas que possibilitem avançar nos processos de análise e intervenção sobre as situações e eventos de riscos que são colocados para os trabalhadores, populações vizinhas às indústrias e ao meio ambiente como um todo. (PORTO; FREITAS, 1997, p. 60)
\end{abstract}

Diante do importante desafio histórico e atual da integração entre Visat e a questão ambiental, o artigo traz resultados de pesquisa sobre a proposta do CRST de Campinas, que desenvolveu nos últimos anos a experiência de atenção integral à saúde na abordagem de riscos químicos. São exemplos de tal atuação: o caso da contaminação ambiental do bairro das Mansões Santo Antônio, onde dois edifícios residenciais foram construídos em uma área que pertencia à empresa Proquímica, que funcionou de 1973 a 1996 realizando atividades para recuperação de solventes (CARNEIRO; NAKAMOTO; VIEIRA, 2008); e o caso da contaminação dos trabalhadores e do território de entorno do Complexo Industrial Shell/Basf/Cyanamid, em Paulínia/SP, que funcionou de 1977 a 2002 formulando e sintetizando uma série de substâncias químicas para a produção de agrotóxicos (REZENDE, 2005).

O Projeto de Vigilância em Postos de Revenda de Combustíveis a Varejo/Postos de Abastecimento (PRCV/PA) também se enquadra nesta perspectiva de atuação e foi considerado exitoso pelos profissionais do referido CRST por atender aos seguintes critérios: ser desenvolvido por equipe multiprofissional; buscar integrar instâncias e profissionais do SUS (intrassetorialidade) e de outras instituições (intersetorialidade); proporcionar a participação dos trabalhadores.

A opção por esse objeto de estudo justificou-se pela necessidade de dar visibilidade à trajetória das ações consideradas exitosas desenvolvidas pelos CRST, bem como a suas potencialidades e dificuldades. Assim, pretendeu-se fornecer subsídios para análise dos problemas e das possibilidades existen- 
tes a fim de apontar caminhos para a superação dos impasses e a construção de práticas de êxito em ST e Ambiente.

\section{Considerações metodológicas do estudo de caso no CRST Campinas}

Neste estudo de caso, realizou-se abordagem qualitativa (MINAYO, 1998; BECKER, 1999; YIN, 2001) mediante entrevistas estruturadas individuais com os seguintes atores envolvidos no projeto entre os anos de 2008 e 2009:

- do CRST: 1 gestor (fonoaudiólogo) e 4 profissionais (1 psicólogo, 2 médicos e 1 enfermeiro);

- da Vigilância em Saúde Municipal (Visa): 1 tecnólogo ambiental, 1 médico e 1 engenheiro;

- da Divisão Sanitária do Trabalho do Centro de Vigilância em Saúde (CVS): 1 fonoaudiólogo; e

- do Centro Estadual de Referência em Saúde do Trabalhador da Bahia (Cesat): 1 gestor ambiental que assessorou o projeto.

Além disso, entrevistamos 2 atores da Fundacentro de Campinas e São Paulo, 1 historiador e 1 químico e 1 profissional médico da SRTE de São Paulo. Foram ainda entrevistados 4 trabalhadores, sendo 2 deles do Sindicato dos Frentistas e 2 da Associação dos Trabalhadores Expostos a Produtos Químicos (Atesq). As 17 entrevistas foram gravadas, transcritas e sistematizadas nos seguintes eixos temáticos: equipe de trabalho, ações desenvolvidas, estratégias de trabalho, experiência em ST, ações consideradas exitosas, trajetória e inserção, potencialidades relacionadas às suas possíveis repercussões e dificuldade.

No mesmo período, a primeira autora participou como observadora de reuniões e seminários das Comissões do Benzeno e do CVS. Ademais, em paralelo à realização da entrevista, foi feita uma busca de documentos históricos e oficiais (planos e relatórios de ações) do CRST.

O instrumento metodológico adotado foi a Análise de Conteúdo (BARDIN, 1977), visando a apreender a presença de núcleos temáticos e submetê-los a uma interpretação mais profunda, relacionando-os à teoria e conceitos do campo ST. No entanto, não procedemos à contagem da frequência das unidades de significação presentes no discurso (MINAYO, 1998).

A pesquisa foi aprovada pelo Comitê de Ética em Pesquisa da Universidade Federal de São Paulo (CEP 1467/06) e houve aprovação de todos os entrevistados mediante assinatura do Termo de Consentimento Livre e Esclarecido.

\section{Saúde do Trabalhador e Ambiente em Campinas/SP}

Campinas localiza-se na região noroeste do Estado de São Paulo, cerca de 100 km da capital, com população de 1.039.297 habitantes (INSTITUTO BRASILEIRO DE GEOGRAFIA E ESTATÍSTICA, 2007), sendo sede de região metropolitana composta por 19 municípios.

A atenção básica em Campinas estrutura-se em 49 Unidades Básicas de Saúde (UBS), 4 serviços de pronto atendimento, 13 módulos de Saúde da Família com 41 equipes de Estratégia de Saúde da Família (ESF). O município tem 14 CRSTs, 3 ambulatórios de especialidades, 2 hospitais universitários, um hospital municipal, maternidades, hospitais privados e filantrópicos (NASCIMENTO; CORREA; NOZAWA, 2007). Estão alocados em cinco distritos de saúde: Norte, Sul, Sudoeste, Noroeste e Leste, cada qual com estrutura de Vigilância em Saúde (Visa), com média de 20 profissionais por equipe. Devido ao processo de descentralização das ações de vigilância do CRST, existem equipes de ST atuantes em cada uma destas Visas que são coordenadas pela Coordenação de Vigilância em Saúde (Covisa).

A rede de saúde municipal teve importante papel histórico no movimento de Reforma Sanitária Brasileira, sendo precursora da proposta de organização do SUS (NASCIMENTO; CORREA; NOZAWA, 2007). De acordo com Dias (1994), com a participação do movimento sindical e dos profissionais da saúde, é criado, em fevereiro de 1987, o Ambulatório de ST de Campinas em uma unidade básica de saúde. Em 1990, esse ambulatório é transformado em Programa de Saúde do Trabalhador (PST), adquire uma sede própria e assume a Coordenação de Acidentes de Trabalho, até então responsabilidade do Instituto Nacional de Previdência Social. Em 1993, o PST torna-se CRST (MEDEIROS, 2001). Em julho de 2003, o CRST é habilitado à Rede Nacional de Atenção Integral à Saúde do Trabalhador (Renast), com nove municípios na sua área de abrangência: Campinas, Americana, Arthur Nogueira, Cosmópolis, Hortolândia, Nova Odessa, Paulínia, Sumaré e Valinhos, com população entre 1,8 a 2 milhões de habitantes.

O CRST carrega uma trajetória marcante no movimento da ST (SATO; LACAZ; BERNARDO, 2004), constituindo-se como importante referência para outros CRST no Estado de São Paulo e no país. Ao longo dessa história, o CRST buscou sucessivos processos de descentralização das ações voltadas para a saúde dos trabalhadores na rede de saúde, primeiramente no atendimento dos trabalhadores acidentados no trabalho, depois no atendimento aos trabalhadores 
com LER e, finalmente, nas ações de Visat para as Visas do município. Nesse processo, a formação dos profissionais do SUS teve papel central no fomento às ações, mesmo com conflitos, conforme relataram os entrevistados.

As atividades de avaliação e planejamento das ações do CRST pautaram essa trajetória, construindo uma experiência marcada pela aproximação com as demais instâncias da rede do SUS e pela priorização de ações capazes de articular vigilância, educação e assistência, assim como de agregar outros atores institucionais e trabalhadores. O relato de um dos trabalhadores trata da importância da prática dos profissionais de saúde, da experiência empírica, dos percursos trilhados e da influência histórica como dispositivos de formação que garantem maior domínio e confiança de atuação dos profissionais, já descrita por Dias et al. (2008): "Na saúde pública, pelo menos em Campinas, tem uma experiência muito boa, de fazer ótimos planejamentos, diversas metodologias, enfim, tem know how pra isso" (Profissional ST 3).

O envolvimento dos profissionais do CRST Campinas nos casos do bairro Mansões Santo Antonio e Shell/Cyanamid/Basf, de Paulínia, propiciou um processo de formação concomitantemente à ação de vigilância. Isso permitiu aos envolvidos maior experiência na relação entre trabalho, saúde e ambiente, especialmente aquela implicada na contaminação química que afetou a saúde dos trabalhadores e da população do entorno, bem como o ambiente, em uma perspectiva participativa e integrada (SANTOS, 2010).

\section{Postos de combustível}

Hoje, sabe-se que a problemática dos postos de combustível, na relação com o ambiente, pela contaminação da água, do solo e do ar, deve ser considerada (SANTOS, 2010). A Cetesb, na qualidade de órgão fiscalizador e regulador das questões relativas ao meio ambiente no Estado de São Paulo, disponibiliza dados relativos às áreas contaminadas, entendidas como aquelas que podem gerar danos à saúde humana, comprometimento dos recursos hídricos, restrições ao uso do solo e danos ao ambiente (CETESB, 2012).

Observa-se, pelos dados oficiais referentes ao Estado de São Paulo (CETESB, 2012), que, em um total de 4.572 áreas classificadas como contaminadas, 3.510 são em postos de combustível, isto é, 76,77\% das áreas registradas pela Cetesb até dezembro de 2012. Tal tendência é evidenciada em Campinas, onde, em 2008, havia 92 áreas contaminadas, 72 delas devido a postos de combustível, cerca de $78 \%$ do total. As principais situações de contaminação, no caso dos postos de combustível, estão relacionadas à arma- zenagem e à infiltração de combustíveis, solventes aromáticos e hidrocarbonetos policíclicos aromáticos (PAM) advindos dos tanques subterrâneos (CETESB, 2012). Os principais meios impactados são subsolos e águas subterrâneas, dentro e fora da propriedade do posto de combustível (CETESB, 2012).

Frise-se que, desde 2001, é obrigatória a licença ambiental da Cetesb para funcionamento dos postos de combustíveis no Estado de São Paulo, renovável a cada cinco anos, conforme Resolução $\mathrm{n}^{\circ} 5$ de 28/03/2001 (SÃO PAULO, 2001). Para a Cetesb (2012), o crescimento das áreas contaminadas por postos de combustível está relacionada a tal programa de licenciamento, o qual exige investigação confirmatória para verificar a situação ambiental e a troca de equipamentos antigos, com mais de 15 anos de operação.

Por outro lado, a Agência Nacional de Petróleo - ANP (2011) informa haver outra questão que também constitui um sério risco à saúde dos frentistas: adulteração de combustíveis. Segundo legislação da ANP, a concentração máxima permitida de benzeno em gasolina automotiva pode variar entre $1 \%$ e 1,5\%. No entanto, a própria agência já encontrou essa substância com 8\% de concentração (COSTA, 2009). Diante deste cenário, a adulteração de combustível com o acréscimo no volume de benzeno também justifica a necessidade de ação não só frente aos danos que estes produtos podem gerar sobre a saúde dos trabalhadores, da população do entorno e dos consumidores, mas também por conta dos danos ambientais que pode gerar.

Pelo fato do benzeno ser uma substância reconhecidamente carcinogênica, considerada a quinta de maior risco à saúde humana pelo Programa de Segurança Química das Nações Unidas (COSTA, 2009), o Acordo Nacional do Benzeno (ANB) proíbe seu uso, exceto por empresas que o produzem ou o utilizem em síntese, como químicas, siderúrgicas e laboratórios, onde o benzeno não pode ser substituído. Essas empresas são cadastradas e devem observar um regulamento próprio, com a constituição de Grupos de Trabalhadores do Benzeno (GTB), que fazem parte das Comissões Internas de Prevenção de Acidentes dessas empresas, como forma do controle social da exposição (MACHADO et al., 2003).

O ANB, firmado e regulamentado em dezembro de 1995, determina a criação da Comissão Nacional Permanente do Benzeno (CNBz), que apresenta prerrogativas para a discussão da proibição do benzeno em produto acabados, dentre os quais a gasolina (MACHADO et al., 2003), bem como para acompanhar a implementação e o cumprimento do Anexo 13A, da Norma Regulamentadora (NR) 15 da Portaria $\mathrm{n}^{\mathrm{o}}$ 3.214, de 08/06/1978, do Ministério do Trabalho e Emprego - MTE (BRASIL, 1978). A comissão é tripar- 
tite, com representação do Governo (MTE, Ministério da Saúde - MS, Ministério da Previdência Social MPS e Ministério do Desenvolvimento da Indústria e Comercio - MDIC), dos Trabalhadores (Central Única dos Trabalhadores, Força Sindical e Confederação Nacional dos Trabalhadores da Indústria) e dos empregadores (Confederação Nacional da Indústria, Associação Brasileira da Indústria Química, Instituto Brasileiro de Petróleo e Gás, Instituto Brasileiro de Siderurgia e Petrobrás) (COSTA, 2009). Ao longo dos anos, foi estimulada a criação das Comissões Estaduais de Acompanhamento do Acordo (CEBz) e das Comissões Regionais (CRBz) nos locais onde existem empresas cadastradas, nos termos do ANB (ARCURI; CARDOSO, 2005).

A CRBz de Campinas foi consolidada, de acordo com os entrevistados, no ano de 2007 e, nesse mesmo ano, o atendimento no CRST Campinas de três trabalhadores frentistas com graves problemas de saúde, como alterações hematológicas, hepatite tóxica e epilepsia, torna-se o evento sentinela que aciona a CRBz. Tal episódio foi elemento disparador favorável para o desenvolvimento do Plano de Vigilância nos Postos de Combustível na cidade.

\section{A trajetória do Projeto de Vigilância nos Postos de Combustível: trabalho inter- disciplinar, intra e interinstitucional}

De acordo com os entrevistados, o projeto dos postos de combustível é elaborado na CRBz, na qual atuam três subgrupos técnicos: de educação, para atividades de formação; de inspeções, para avaliar o cumprimento do acordo; e de vigilância, visando avaliar a exposição ao benzeno existente na gasolina. Inicialmente, o subgrupo da vigilância, responsável pelo projeto, era composto por duas profissionais, uma vinculada ao CRST e outra à Fundacentro de Campinas. Para os entrevistados, com a compreensão desses profissionais sobre a complexidade sistêmica da problemática dos postos de combustível em relação à saúde e ao ambiente, o primeiro passo para uma intervenção articulada foi ampliar a rede de pessoas envolvidas. As atividades de formação, segundo eles, foram determinantes para tanto. A formação com profissionais de saúde da rede municipal, vinculada à Vigilância Ambiental e às Visas de Campinas, favoreceu a entrada de novos profissionais na composição da equipe do projeto e redirecionou o foco da ação, dando-se prioridade aos postos com contaminação do solo e, por consequência, à investigação das condições de saúde dos trabalhadores desses Postos e da população do seu entorno:

Em cima dessa sensibilização dos grupos de vigilância ambiental e de saúde do trabalhador foi construído o projeto de forma coletiva, a gente fazia reunião, passava o projeto, retirava objetivo e punha objetivo, todo aquele papo de construção realmente coletiva foi feito. Acho que isso ajudou o pessoal a se sensibilizar e se organizar em cima do projeto. (Profissional Fundacentro 2)

Conforme disseram os entrevistados, foram inúmeras as reuniões ao longo da concepção da proposta, dentro e fora da CRBz de Campinas, tanto para discuti-la internamente, quanto para apresentá-la para outras instituições, reforçando sua dimensão ampliada. O desfecho desses encontros é que esta atividade passa a ser associada àquelas já desenvolvidas pelos profissionais das Visas, nas áreas contaminadas, a partir dos programas Vigi-Solo e Vigi-Água no âmbito municipal. Para implementar tal atuação, os entrevistados relataram que a CRBz realizou um curso com aulas teóricas e práticas para aplicação do roteiro de inspeção, utilizado na experiência de vigilância em postos de combustível do Centro de Saúde do Trabalhador (Cesat) da Bahia, por demanda do Ministério Público daquele estado. Este roteiro foi discutido, aplicado e reelaborado em grupo. Assim, com as atividades formativas e a realização das reuniões, somam-se esforços de diferentes profissionais e instituições em torno de um problema comum, com a definição e a execução de atividades que ganham uma dimensão coletiva e interdisciplinar, conforme relataram os profissionais envolvidos e que foram entrevistados.

Considerando esses novos elementos e com dados da ANP, do INSS e da Cetesb, no primeiro semestre de 2008, o Projeto dos Postos de Combustível de Campinas tem sua elaboração finalizada no termo de referência intitulado "Projeto de Vigilância em Postos de Revenda de Combustíveis a Varejo/ Postos de Abastecimento (PRCV/PA)" (SECRETARIA MUNICIPAL DE SAÚDE DE CAMPINAS, 2009c), com a definição de objetivos, metas, parceiros e cronograma das atividades. O termo de referência contempla os problemas da adulteração do combustível, da contaminação de solo, água e ar, da atenção integral à saúde dos trabalhadores e da população do entorno. O plano envolvia a execução de ações de vigilância, assistência e educação em saúde, com abordagem voltada para trabalhadores, sindicatos, proprietários dos postos e profissionais das unidades de saúde, localizados nas regiões dos postos em área contaminada, a fim de instrumentalizá-los a respeito dos riscos e para o atendimento da população do entorno de uma forma diferenciada. De acordo com os entrevistados, tal termo foi apresentado ao Sindicato Patronal dos Postos de Combustível, à SRTE e à Cetesb.

Conforme relatam os profissionais de saúde entrevistados, a partir de 2008 a Secretaria de Vigilância em Saúde (SVS), do Ministério da Saúde, com representação na $\mathrm{CNBz}$, iniciou a elaboração de 
um projeto, em âmbito nacional, relativo à mesma questão. Os principais grupos envolvidos nessa elaboração são os de Campinas, que conta com instituições como CRST, Vigilância Municipal e CRBz; de Curitiba, cujo maior parceiro era o Ministério do Trabalho e Emprego; e de Salvador, desenvolvido pelo Cesat. Os profissionais desses grupos foram inseridos no projeto piloto, que subsidiou a discussão para a construção de uma política nacional: "O projeto nacional está buscando experiências e modelos regionais e locais. E nós somos esses modelos que eles estão usando" (Profissional Visa 3).

Da mesma forma, a Divisão de Vigilância Sanitária do Trabalho, do CVS, da Secretaria de Estado da Saúde de São Paulo (SES/SP), com representação na $\mathrm{CEBz}$, dentro de seus programas prioritários, possui um deles com interface à proposta, o "Programa de Saúde do Trabalhador em Exposição ao Benzeno". De acordo com profissional entrevistada, tal programa foi apresentado no Plano Estadual de Saúde 2008-2011 e pactuado com os municípios no Plano de Ação de Vigilância Sanitária, sendo prevista a capacitação e atuação dos profissionais das vigilâncias municipais em postos de combustível.

O Sindicato dos Empregados em Postos de Serviços de Combustíveis e Derivados do Petróleo de Campinas e Região (Sindicato dos Frentistas) participou do projeto desde o início. Os dirigentes sindicais entrevistados estimavam 5 mil trabalhadores associados ao sindicato e, apesar da alta rotatividade da categoria, consideravam que cerca de 90\% eram sindicalizados. Além da sede de Campinas, o sindicato possui três subsedes: em Americana, Limeira e Mogi Mirim.

No momento das entrevistas, os sindicalistas envolvidos haviam ingressado recentemente na proposta e expressaram a necessidade de conhecerem melhor a ação:

\begin{abstract}
Nós vamos ter que acompanhar e dar um encaminhamento maior, porque nós temos uma preocupação muito grande com a saúde do trabalhador e é uma discussão muito aprofundada, porque a nossa categoria trabalha diretamente com os produtos inflamáveis, não só com produtos inflamáveis, com produtos insalubres, produtos químicos e tem o contato direto. (Trabalhador 1)
\end{abstract}

Já os trabalhadores representantes da Atesq, membros do Conselho Gestor do CRST, relataram, nas entrevistas, que sabiam das pesquisas existentes sobre a temática, expressavam conhecimento sobre os transtornos à saúde decorrentes da exposição continuada aos produtos químicos pela precocidade e gravidade dos casos e incorporaram o conceito de precaução: "É preferível e mais saudável trabalhar em cima da precaução, porque nós estamos falando da saúde” (Trabalhador 3). Esse conceito é expres- so no artigo 255 da Constituição Federal (1988), em Leis ambientais e no Código Sanitário do Estado de São Paulo, que se refere à:

[...] desencadear ações preventivas (de antecipação) em caso de incerteza, dúvida; transferir a responsabilidade da prova aos proponentes da atividade; investigação ampla de alternativas para a ação prejudicial; aumentar a participação pública na tomada de decisões. (KRIEBEL; TICKNER apud REZENDE, 2005, p. 53)

Frise-se que tais trabalhadores sinalizavam a importância da incorporação desse conceito também no caso do Projeto dos Postos de Combustível (AUGUSTO; FREITAS, 1998).

Para alguns dos profissionais entrevistados, à medida em que ocorre a pactuação das ações de vigilância nos postos de combustível no âmbito do SUS, nos níveis nacional, estadual e municipal, elas tendem a convergir para uma ação transversal, visto que se tornou uma demanda de trabalho dos diferentes atores, fortalecendo seu compromisso com a produção de conhecimento e com a ação interinstitucional (MACHADO, 2005b).

Os resultados preliminares das ações do projeto serão apresentados a seguir.

\section{O desenvolvimento de ações de vigilân- cia nos postos de combustível e as mudanças na abordagem do processo saúde-doença}

Em Campinas, o Projeto de Vigilância nos Postos de Combustível foi inserido como atividade do programa de exposição a produtos químicos e riscos à saúde humana, da Visa municipal. Cada distrito possuia profissionais do núcleo de Vigilância Epidemiológica, de Saúde do Trabalhador, de Saúde Ambiental e/ou do Núcleo de Vigilância Sanitária envolvidos. Das ações de vigilância nos postos de combustível, participavam equipes compostas por três profissionais: médico, enfermeiro, engenheiro de segurança e/ou tecnólogo em saúde ambiental. O principal instrumento utilizado era o Roteiro de Vistoria de Ambientes e Processos de Trabalho de Postos de Combustíveis a Varejo e Postos de Abastecimento (SECRETARIA MUNICIPAL DE SAÚDE DE CAMPINAS, 2009b), com dados sobre o posto em si, seus trabalhadores e as condições ambientais de exposição. "[...] desenharam junto com a gente uma proposta de ação desse projeto. O que nós vamos fazer no posto de combustível, o que nós vamos olhar, isso em conjunto" (Profissional Visa 1).

Quanto ao desenvolvimento das ações, os entrevistados disseram que, ao chegar aos postos, a equipe procurava conversar com o responsável presente 
naquele momento e era aplicado o roteiro para verificação in loco da veracidade das respostas. Para eles, a equipe buscava dialogar com os trabalhadores, mesmo não existindo a inserção do sindicato nessas atividades, que ficaram restritas aos profissionais da vigilância em cada distrito. Os profissionais falaram da possibilidade de intervenção no momento da vigilância ou posteriormente a ela, tomando por referência a um banco de dados dessas informações.

De acordo com os profissionais entrevistados, a principal lei utilizada nas atividades de vigilância dos postos de combustível era a Lei Federal do MTE $\mathrm{n}^{\circ}$ 6.514/1977 (BRASIL, 1977) e a Portaria MTb $\mathrm{n}^{\circ}$ 3.214/1978 (BRASIL, 1978), que trata das Normas Regulamentadoras (NR). Destas, eram adotadas, nas ações de vigilância para vistoriar aspectos relacionados ao risco ambiental, à saúde ocupacional e às instalações elétricas, as NR 7, 9 e 10, respectivamente. Emanada do Ministério da Saúde, foram referidas, pelos entrevistados, a Portaria $\mathrm{n}^{\circ}$ 518/GM (BRASIL, 2004), que estabelece os procedimentos e as responsabilidades relativos ao controle e à vigilância da qualidade da água para consumo humano e seu padrão de potabilidade, e a Portaria $n^{\circ}$ 3.120/1998 (BRASIL, 1998), instrução normativa que orienta estados e municípios nas ações de Visat no âmbito do SUS.

Na esfera estadual, o Código Sanitário do Estado de São Paulo, Lei Estadual no 10.083/1998 (SÃO PAULO, 1998), foi considerado, pelos profissionais entrevistados, o principal instrumento base para as ações da vigilância, assim como a Portaria do CVS $\mathrm{n}^{\circ}$ 02/2007 (SÃO PAULO, 2007), que obriga a apresentação de uma série de documentos no ato do cadastramento da solução alternativa coletiva de abastecimento de água para consumo humano proveniente de mananciais subterrâneos, como os poços profundos.

Ainda em relação ao desenvolvimento das ações de vigilância do projeto, após a realização de duas inspeções (piloto) em cada distrito de saúde, realizou-se reunião no CRST com os profissionais de todas as Visas para apresentação dos resultados preliminares, avaliação do roteiro e compartilhamento das experiências acumuladas. Conforme programado, o CRST de Campinas realizou o atendimento dos trabalhadores dos postos, tendo como principal instrumento a ficha de acolhimento em ST para exposição a riscos químicos (SECRETARIA MUNICIPAL DE SAÚDE DE CAMPINAS, 2009a), objetivando coletar dados sobre os trabalhadores e sua saúde. A ficha foi elaborada pelos profissionais do CRST, da Visa e da CRBz, tomando por base os procedimentos de atenção à saúde diante dos riscos químicos: “(...) demos uma reestruturada no que já tinhamos, porque nos baseamos no acolhimento da experiência da Shell. Então isso realmente nos facilitou bastante" (Profissional ST 12).
Além do atendimento dos trabalhadores, previu-se a realização de grupos focais com tais trabalhadores para discutir o processo de trabalho e os riscos à saúde e ao ambiente a fim de captar outros elementos não contemplados na ficha. Após a finalização da etapa piloto, os profissionais envolvidos concluíram as adequações ao protocolo de vigilância e à ficha de acolhimento dos trabalhadores a fim de subsidiar a ação tanto na rede de saúde de Campinas, quanto em outros municípios.

\section{Potencialidades e desafios futuros}

Quando da realização da pesquisa ora relatada, o Projeto dos Postos de Combustível estava na fase inicial, com algumas alterações no seu cronograma e ganhando amplitude com a entrada de novos atores. Um aspecto fundamental é que o processo de formação, seja através de cursos oferecidos pelas Comissões do Benzeno, seja dos cursos de especialização em ST organizados pelo próprio CRST de Campinas em parceria com a SES/SP e a Universidade Estadual de Campinas (Unicamp), sensibilizou e agregou os profissionais de saúde da rede e de outras instituições, que passaram a participar das sucessivas reuniões de planejamento das ações junto aos postos de combustível. Tal participação tem trazido maior envolvimento dos profissionais com a questão, na medida em que passam a se sentir integrantes de uma proposta que auxiliaram a construir (CAMPOS; AMARAL, 2007).

Você tem uma construção de várias instituições e dentro dessas instituições, pessoas, que tem um olhar, querem trabalhar junto e entendem que não estão ali só pra se aposentar (risos) e sabe que pode ser mais eficiente se você trabalhar integrado. (Profissional ST 1)

A garantia de um trabalho verdadeiramente coletivo e integrado depende de inúmeros aspectos, dentre os quais a conexão dos diferentes processos de trabalho envolvidos, o estabelecimento de consensos quanto aos objetivos e resultados pelo conjunto dos profissionais, bem como a definição da maneira adequada para atingi-los (RIBEIRO; PIRES; BLANK, 2004). A necessidade da aproximação entre os atores e suas instituições em torno de um objeto ou plano comum, como é o caso do problema laboral e ambiental dos postos de combustível, demanda uma atenção especial sobre o processo formativo, fundamental para a disseminação da informação, para a produção de um conhecimento compartilhado, de uma linguagem também compartilhada, integradora e da construção das relações interpessoais, institucionais e políticas entre os sujeitos. 
Para os entrevistados, o projeto ampliou o olhar dos atores envolvidos sobre a exposição ao risco químico no que se refere à construção de indicadores de saúde e ambientais, podendo ter como repercussões a melhoria das condições de trabalho nos postos de combustível, o aumento do controle social e a regulamentação dos processos relacionados à produção, à distribuição e ao consumo dos combustíveis, além de tratar do problema do uso do benzeno na gasolina e do processo de descontaminação das áreas afetadas.

Segundo Dias et al. (2009), ST e Saúde Ambiental são transversais e, portanto, exigem políticas públicas que articulem os diferentes setores sociais responsáveis pela produção e geração de riscos para a saúde dos trabalhadores, da população do entorno e do ambiente, assim como os setores responsáveis pela atenção integral, vigilância e reparação de danos. Dessa forma, o mérito do projeto, conforme relatado pela totalidade dos profissionais entrevistados, diz respeito ao caráter articulador com o qual a proposta foi construída, agregando profissionais de diversas profissões, especialidades e de diferentes instituições. O principal aspecto dessa integração, considerado nas entrevistas, refere-se ao comprometimento dos profissionais, à medida que o diálogo permanente, nas capacitações e nas reuniões da equipe do projeto, favoreceu tanto o entendimento do trabalho de cada profissional, quanto a unificação de esforços em comum:

Acho que esse projeto, na verdade, ele já está trazendo muita mudança, muito envolvimento (...). Eu acho essa estratégia inovadora e muito enriquecedora, está ajudando a gente a entender o trabalho de cada um, está integrando mais. (Profissional ST 2)

O sentimento de coautoria da ação é um poderoso instrumento para vincular o profissional à uma dada organização ou projeto (CAMPOS; AMARAL, 2007). Portanto, o que parece ter contribuído com esse envolvimento é a participação dos profissionais na construção do planejamento das ações, do cronograma da proposta, dos instrumentos a serem usados, com a realização de ações em conjunto e avaliações periódicas em reuniões específicas. Ou seja, os profissionais participaram das diferentes etapas projeto, de modo coletivo e ampliado: "[...] o processo de trabalho a gente tem que construir junto com as pessoas, pras pessoas curtirem participar do projeto, todos" (Profissional Visa 2). Esse encontro permitiu a formulação e ajustes dos instrumentos de inspeção nos postos de combustível e de acolhimento dos trabalhadores no CRST, essenciais para orientação das ações práticas de vigilância e assistência em saúde, respectivamente.

O conhecimento adquirido sobre como integrar profissionais, trabalhadores e instituições é extremamente referenciado pelos entrevistados, conforme ilustrado abaixo:
Quando você passa a discutir sentado na mesma mesa com a equipe, todo mundo junto, na mesma roda, você troca definitivamente os olhares. E o que é bem interessante é um objeto totalmente novo pra saúde do trabalhador e pra vigilância ambiental. (Profissional Visa 3)

Ademais, a proposta agrega o conhecimento histórico do CRST de Campinas de ações planejadas em que a articulação intra e intersetorial tem sido produzida para agregar pessoas e instituições, numa intervenção pensada coletivamente. A formação dessa rede em torno de um mesmo objeto propicia a produção de um saber interdisciplinar, muito potente na intervenção, mas que consome maior tempo para seu amadurecimento e execução.

O trabalho em grupo envolve relações entre pessoas, sentimentos, expectativas, conhecimentos, interesses, afetos e desafetos, entre outras tantas questões, assim como demanda o estabelecimento de vínculos entre os sujeitos (CAMPOS, 2007). Nesse sentido, "a dificuldade é a integração, a articulação, você vai estar trabalhando com vários órgãos, com pensamentos diferentes e interesses diferentes" (Profissional Cesat). A construção de ações em redes intersetorais demanda implicação, esforço e habilidades das pessoas, que constroem o trabalho institucional, pois envolve diferentes perspectivas e espaços de poder de coorporações e instituições (MACHADO; PORTO, 2003).

Vale ressaltar que alguns entrevistados expressaram que o envolvimento das instituições não se dá na mesma proporção, algumas participam ativamente, enquanto outras são referências de apoio para determinadas situações. De acordo com Machado e Porto (2003), as redes construídas nas ações de Visat são dinâmicas, de estabilidade provisória, e traduzem a conjunção e a integração de diferentes atores e interesses frente a problemas específicos, assim como a força dos trabalhadores e do setor saúde na sociedade.

Outro aspecto importante considerado por grande parte dos entrevistados diz respeito à integração entre ST e ambiente:

Acho que tem este potencial, diferente de boa parte dos outros locais do Brasil, que é de fato você ter essa discussão da saúde ambiental com a saúde do trabalhador. [...] E essa discussão do posto de gasolina está funcionando como um movimento pra fazer essa integração, gerando inclusive do ponto de vista concreto todas as dificuldades que isso tem. (Profissional SRTE)

As dificuldades apontadas pelos entrevistados consistem naquelas relativas ao trabalho em grupos com diferentes formações profissionais, saberes e vínculos institucionais, ao que se alia a sobrecarga de trabalho.

Porque todo mundo tem uma demanda muito grande, a unidade de saúde, os profissionais que estão envolvidos. Você conseguir que eles também consi- 
gam absorver mais essa nova demanda, muitas vezes não é fácil. (Profissional ST 2)

O trabalho coletivo, conforme referem alguns entrevistados, requer muita criatividade e "jogo de cintura” para mediar conflitos e situações inusitadas que ocorrem no cotidiano do trabalho em ST, evidenciando as incertezas e os imprevistos presentes no processo de trabalho em saúde. Situações como tratar da saúde dos trabalhadores com donos de postos que adulteram combustíveis demandam dos profissionais em ST habilidade em lidar com a imprevisibilidade do seu trabalho em processos de negociação permanentes. Isto leva a pensar o quão desafiador foi a execução prática do Projeto, demonstrando que os sujeitos envolvidos estão buscando, incessantemente, a melhor forma de trabalhar, em um movimento para dominar os aspectos limitadores das suas ações, até porque continuam a desenvolver nas instituições de origem outras atividades, o que também é determinante do tempo de trabalho disponível para execução da ação de Vigilância dentro de um cotidiano de trabalho já sobrecarregado.

Apesar disso, observamos a importância das relações intersubjetivas em ST para a construção do trabalho potencialmente integrado, que é expresso na motivação dos sujeitos envolvidos em dedicar seu trabalho para a produção de saúde. Na experiência analisada, os entrevistados demonstram interesse e vontade de aprofundar o conhecimento sobre a realidade e aprimorar suas práticas, bem como demonstraram a necessidade de estabelecer redes e fortalecer alianças entre eles e as instituições de origem, no sentido de aperfeiçoarem suas intervenções, a fim de produzir mudanças nas relações entre saúde e doença dos trabalhadores no cenário atual.

Por outro lado, há relatos das dificuldades de um trabalho em torno de um objeto ainda pouco conhecido pelos profissionais de saúde, ou seja, sem aparato teórico e técnico definido sobre a relação entre trabalho, saúde e ambiente em postos de combustível. Além disso, há relatos que os maiores conflitos ocorreram quando as ações interferiam nos processos de trabalho dos postos de combustível.

Frise-se que o compromisso do campo ST em transformar os processos de trabalho pressupõe agir nas relações entre capital e trabalho, marcadas por conflitos e relações de poder. Diante disso, garantir a continuidade da ação frente à rotatividade de profissionais e às descontinuidades e mudanças políticas dentro da gestão pública municipal é uma tarefa a ser considerada para qualquer proposição no campo (LACAZ, 2010).

No que diz respeito aos desafios da gestão do trabalho em ST, os entrevistados acreditam que o maior deles seja a incipiente formação de profissionais no campo ST, mesmo dentre aqueles com formação em Saúde Pública. Além disso, ampliar a abrangência das ações do nível municipal para o regional também é apontado como uma importante dificuldade no cenário atual.

\section{Considerações finais: tecendo redes de Saúde do Trabalhador e Ambiente}

Uma característica marcante da experiência analisada é a formação de redes intra e interinstitucionais em torno de projeto de intervenção definido como prioritário (SANTOS; LACAZ, 2011). O projeto apresentou-se como proposta de ação transversal, no sentido de agregar pessoas e instituições em torno de um problema complexo, nos moldes da constituição de "comandos técnicos estratégicos”. Ou seja, comandos em torno de objetos e experiências concretas, que visam o acompanhamento das situações definidas e construídas coletivamente (MACHADO, 2005b). Nesse caso, a intervenção através da construção de redes de Visat revela-se instrumento estratégico para produzir transformações na defesa da saúde dos trabalhadores e do ambiente.

Dessa forma, outra característica marcante da experiência é apresentar possibilidades de transcender a abordagem do processo saúde e doença, pautada tradicionalmente por ações médico-assistenciais individuais, na perspectiva de ações que visam à prevenção, à promoção e à vigilância em saúde, trabalho e ambiente, com a participação dos trabalhadores. As tecnologias de trabalho (MEHRY, 2000) utilizadas no projeto envolvem menos máquinas e instrumentos e mais recursos teóricos, técnicos e relações intersubjetivas entre os diferentes atores. Aqui é relevante apontar a mudança pela abordagem multiprofissional da problemática, com importantes ações e estratégias interdisciplinares e intersetoriais, e principalmente pela possibilidade potencial de fornecer uma Atenção Integral à Saúde dos Trabalhadores a partir da articulação das ações de educação, vigilância e assistência à saúde na mesma intervenção.

Frise-se que a prática de saúde é submetida a determinantes sociais, políticos e econômicos (CAMPOS, 2007). Além disso, as relações entre trabalho, saúde e ambiente ocorrem no entrecruzamento dos desígnos do capital com as possibilidades de transformação social (LACAZ, 2007). Apesar do caso aqui analisado ser singular e específico, ele aponta para a busca de novos caminhos no campo ST, frente ao contexto global e das políticas de saúde nos âmbitos municipal, estadual e nacional, visto buscar a execução de ações integradas de vigilância, o que poderá contribuir para 
trazer elementos propositivos na construção de novas experiências exitosas no campo ST.

Nesse sentido, o projeto dos postos apresentava-se, nessa fase, como potencial trabalho integrado entre produção, saúde e ambiente, de caráter interdisciplinar, com envolvimento intra e interinstitucional, com a participação dos trabalhadores representantes da Atesq e frentistas, revelando que a ação se apropria claramente dos referenciais do campo ST (LACAZ, 1996; LACAZ, 2007).

O projeto preconizava a relação entre ST, as Comissões do Benzeno e os profissionais das Visa, em especial dos programas Vigi-solo e Vigi-água (BRASIL, [2006]) e apresentava-se como uma ação necessária em todos os municípios do Estado de São Paulo, quiçá do país, pela gravidade dos problemas de saúde frente à exposição direta ou indireta, nas áreas contaminadas, com impactos sobre o ambiente. Nesse caso, fica evidente a importância da análise dos riscos à saúde e ambientais, decorrentes dos Postos de Combustível, antes mesmo de sua instalação (PORTO, 2005).

Consideramos que a construção de projetos em ST com temáticas transversais contribui para o desenvolvimento de estratégias interdisciplinares em redes formadas por diferentes profissionais, trabalhadores e instituições, em torno do mesmo objeto. Isso fortalece a ação e mobiliza os sujeitos para o enfrentamento de situações em que uma atuação isolada seria insuficiente para transformar a realidade do trabalho. À medida que a rede é tecida, pode proporcionar espaços ímpares de integração de conhecimentos, experiências e competências dos sujeitos, favorecendo visões compartilhadas e abrangentes sobre os problemas analisados, unindo produção do conhecimento e transformação social (PORTO; ALMEIDA, 2002; SANTOS, 2010).

Como a pesquisa aqui relatada ancorava-se na experiência do cotidiano do trabalho em saúde, ela é datada e limitada, pois representa uma fotografia de um processo dinâmico e em transformação. Os sujeitos envolvidos na experiência continuavam tecendo a mudança no dia-a-dia de trabalho, em uma trama repleta de dificuldades e potencialidades, marcada pela criatividade, pela militância, pelo compromisso ético com a vida e a convicção de que, apesar de ainda serem poucos, juntos poderão escrever mais uma página da história do campo ST.

\section{Contribuições de autoria}

Santos, A. P. L: desenvolveu a pesquisa, analisou os dados e elaborou o artigo. Lacaz, F.: orientou a pesquisa, participou da elaboração do artigo e da revisão final do texto.

\section{Referências}

\section{AGÊNCIA NACIONAL DO PETRÓLEO. Postos} revendedores autuados e/ou interditados por problemas de qualidade dos combustíveis. 2011. Disponível em: $<$ www.anp.gov.br/?pg $=24870 \& \mathrm{~m}=\& \mathrm{t} 1=\& \mathrm{t} 2=\& \mathrm{t} 3=\& \mathrm{t}$ $4=\& \operatorname{ar}=\& \mathrm{ps}=\&$ cachebust $=1277256760568>$. Acesso em: 19 dez. 2011.

ARCURI, A. S. A.; CARDOSO, L. M. N. (Org.). Acordo e legislação sobre o benzeno 10 anos. São Paulo: Fundacentro, 2005.

AUGUSTO, L. G. S.; FREITAS, C. M. O princípio de precaução no uso de indicadores dos riscos químicos ambientais em Saúde do Trabalhador. Ciência e Saúde Coletiva, Rio de Janeiro, v. 3, n. 2, p. 85-95, 1998.

BAGNARA, S.; BIOCCA, M.; MAZZONIS, D. G. Trends in Occupational Health and Safety Policy in Italy. International Journal of Health Services, Baltimore, v. 11, n. 3, p. 431-450, 1981.

BARCELLOS, C.; QUITÉRIO, L. A. D. Vigilância ambiental em saúde e sua implantação no SUS.
Revista de Saúde Pública, São Paulo, v. 40, n. 1, p. 170177, 2006.

BARDIN, L. Análise de Conteúdo. Lisboa: Editora 70, 1977.

BECKER, H. Observação social: estudos de casos. In: Métodos de Pesquisa em Ciências Sociais. São Paulo: Hucitec, 1999.

BRASIL. Constituição (1988). Diário Oficial [da] República Federativa do Brasil, Brasília, DF, 05 out. 1988. Disponível em: < http://www.planalto.gov.br/ ccivil_03/constituicao/Constituicao.htm > . Acesso em: 21 ago. 2013.

. Ministério da Saúde. Fundação Nacional de Saúde. Vigilância ambiental em saúde. Brasília: Funasa, 2002.

. Ministério da Saúde realiza ações em saúde ambiental. [2006]. Disponível em: < http:// portal.saude.gov.br/portal/saude/visualizar_texto. cfm?idtxt=24236 > . Acesso em: 1 jun. 2010. 
BRASIL. Ministério da Saúde. Portaria nº 518/GM, de 25 de março de 2004. Estabelece os procedimentos e responsabilidades relativos ao controle e vigilância da qualidade da água para consumo humano e seu padrão de potabilidade. Disponível em: < http://dtr2001. saude.gov.br/sas/PORTARIAS/Port2004/GM/GM-518. htm >. Acesso em: 04 nov. 2013.

. Portaria no 3.120, de 01 de julho de 1998. Dispõe sobre a Instrução Normativa de Vigilância em Saúde do Trabalhador. In: _. . Legislação em Saúde: Caderno de Legislação em Saúde do Trabalhador. 2. ed. Brasília: Ministério da Saúde, 2005.

. Lei $\mathrm{n}^{\circ}$ 6.514, de 23 dezembro de 1977 .

Altera o capítulo V, titulo II, da consolidação das Leis Trabalhistas relativo à segurança e medicina do trabalho. Disponível em: < http://www.planalto.gov.br/ ccivil 03/leis/16514.htm>. Acesso em: 04 nov. 2013.

. Ministério do Trabalho. Portaria n⿳0 3.214, de 08 de junho de 1978. Aprova as Normas Regulamentadoras - NR - do Capítulo V, Título II, da Consolidação das Leis do Trabalho, relativas a Segurança e Medicina do Trabalho. Disponível em: <http://portal.mte.gov.br/data/files/FF8080812BE914E 6012BE96DD3225597/p_19780608_3214.pdf > . Acesso em: 04 nov. 2013.

CAMPOS, G. W. S. Saúde Paidéia. 3. ed. São Paulo: Hucitec, 2007.

CAMPOS, G. W. S.; AMARAL, M. A. A clínica ampliada e compartilhada, a gestão democrática e redes de atenção como referenciais teóricooperacionais para a reforma do hospital. Ciência e Saúde Coletiva, Rio de Janeiro, v. 12, n. 4, p. 849-859, 2007.

CARNEIRO, F. G.; NAKAMOTO, C. M.; VIEIRA, O. A. Estudo sobre a percepção dos moradores da região com contaminação ambiental causada pela empresa Proquímica. Revista Ciências do Ambiente On-Line, Campinas, v. 4, n. 1, p. 67, 2008. Resumo. Disponível em: <http://www2.ib.unicamp.br/revista/be310/ index.php/be310/article/viewFile/133/98 > . Acesso em: 25 nov. 2013.

CASTLEMAN, B. Double standard for industrial hazards. International Journal of Health Services, Baltimore, v. 13, n. 1, p. 5-14, 1983.

CETESB. Diretoria de Controle e Licenciamento Ambiental. Texto explicativo: Relação de áreas contaminadas e reabilitadas no Estado de São Paulo, dezembro 2012. Disponível em: <http://www.cetesb. sp.gov.br/userfiles/file/areas-contaminadas/2012/textoexplicativo.pdf>. Acesso em: 7 ago. 2013.

COSTA, D. F. Prevenção da Exposição ao Benzeno no Brasil. 2009. 179 f. Tese (Doutorado em Medicina)Faculdade de Medicina, Universidade de São Paulo, São Paulo, 2009.

DIAS, E. C. A atenção à saúde dos trabalhadores no setor saúde (SUS), no Brasil: realidade, fantasia, utopia? 1994. 335 f. Tese (Doutorado em Ciências
Médicas)-Faculdade de Ciências Médicas, Unicamp, Campinas, 1994.

DIAS, E. C. et al. Implementação das ações de saúde do trabalhador no SUS no Estado de Minas Gerais, no período de 2002-2007: diagnóstico de situação e recomendações para o aperfeiçoamento do processo. Relatório técnico-científico. Belo Horizonte: Cerest, 2008. Mimeografado.

. Saúde Ambiental e Saúde do Trabalhador na Atenção Primária à Saúde, no SUS: oportunidades e Desafios. Ciência e Saúde Coletiva, v. 14, n. 6, p. 20612070, Rio de Janeiro, 2009.

INSTITUTO BRASILEIRO DE GEOGRAFIA E ESTATÍSTICA. Contagem da população, 2007. Disponível em: <http://www.ibge.gov.br/home/ estatistica/populacao/contagem2007/defaulttab.shtm > Acesso em: 1 jun. 2010.

LACAZ, F. A. C. O campo da Saúde do Trabalhador: resgatando conhecimentos e práticas sobre as relações Trabalho-Saúde. Cadernos de Saúde Pública, Rio de Janeiro, v. 23, n. 4, p. 757-766, 2007.

. Política Nacional de Saúde do Trabalhador: desafios e dificuldades. In: LOURENÇO, E. A. S. (Col.) O avesso do trabalho II: trabalho precarização e saúde do trabalhador. São Paulo: Expressão Popular, 2010. p. 199-230.

. Saúde do trabalhador: um estudo sobre as formações discursivas da academia, dos serviços e do movimento sindical. 1996. $432 \mathrm{f}$. Tese (Doutorado em Ciências Médicas)-Faculdade de Ciências Médicas, Unicamp, Campinas, 1996.

MACHADO, J. M. H. Ação transversal intersetorial: entre o racional e o conjuntural. Rio de Janeiro, 2005b. Disponível em: <http://www.saudeetrabalho.com.br/ download_2/acao-transversal.doc $>$. Acesso em: 14 ago. 2013.

. Alternativas e processos de Vigilância em Saúde do Trabalhador: a heterogeneidade da intervenção. 1996. 166 f. Tese (Doutorado em Saúde do Trabalhador e Ecologia Humana)-Centro de Estudos da Saúde do Trabalhador e Ecologia Humana, Escola Nacional de Saúde Pública, Fiocruz, Rio de Janeiro, 1996.

. A propósito da Vigilância em Saúde do Trabalhador. Ciência e Saúde Coletiva, Rio de Janeiro, v. 10, n. 4, p. 797-807, 2005a.

. Processo de Vigilância em Saúde do Trabalhador. Cadernos de Saúde Pública, Rio de Janeiro, v. 13, supl. 2, p. 33-45, 1997.

MACHADO, J. M. H. et al. Alternativas e processos de vigilância em saúde do trabalhador relacionado à exposição do Benzeno no Brasil. Ciência e Saúde Coletiva, Rio de Janeiro, v. 8, n. 4, p. 913-921, 2003.

MACHADO, J. M. H.; PORTO, M. F. S. Promoção da saúde e intersetorialidade: a experiência da Vigilância em Saúde do Trabalhador na construção de redes. 
Epidemiologia e Serviços de Saúde, Brasília, v. 12, n. 3, p. 121-131, 2003.

MEDEIROS, M. A. T. O Centro de Referência em Saúde do Trabalhador de Campinas: trajetória de uma experiência. 2001. 220 f. Dissertação (Mestrado em Sociologia)-Instituto de Filosofia e Ciências Humanas, Unicamp, Campinas, 2001.

MINAYO, M. C. S. O desafio do conhecimento: pesquisa qualitativa em saúde. 5. ed. São Paulo; Rio de Janeiro: Hucitec; Abrasco, 1998.

NASCIMENTO, E. P. L.; CORREA, C. R. S.; NOZAWA, M. R. O município de Campinas e a organização da rede municipal de saúde. Revista de Ciências Médicas, Campinas, v. 16, n. 3, p. 161-173, 2007.

PORTO, M. F. S. Saúde do trabalhador e o desafio ambiental: contribuições do enfoque ecossocial, da ecologia política e do movimento pela justiça ambiental. Ciência e Saúde Coletiva, Rio de Janeiro, v. 10, n. 4, p. 829-839, 2005.

PORTO, M. F. S.; ALMEIDA, G. E. S. Significados e limites das estratégias de integração disciplinar: uma reflexão sobre as contribuições da saúde do trabalhador. Ciência e Saúde Coletiva, Rio de Janeiro, v. 7, n. 2, p. 335-347, 2002.

PORTO, M. F. S.; FREITAS, C. M. Análise de riscos tecnológicos ambientais: perspectivas para o campo da Saúde do trabalhador. Cadernos de Saúde Pública, Rio de Janeiro, v. 13, supl. 2, p. 59-72, 1997.

REZENDE, J. M. P. O caso Shell/Cyanamid/Basf: Epidemiologia e informação para o resgate de uma precaução negada. 2005. 206 f. Tese (Doutorado em Epidemiologia)-Faculdade de Ciências Médicas, Unicamp, Campinas, 2005.

RIBEIRO, E. M.; PIRES, D.; BLANK, V. L. G. A teorização sobre processo de trabalho em saúde como instrumental para análise do trabalho no Programa Saúde da Família. Cadernos de Saúde Pública, Rio de Janeiro, v. 20, n. 2, p. 438-446, 2004.

RIGOTTO, R. M. Saúde Ambiental e Saúde dos Trabalhadores: uma aproximação promissora entre o verde e o vermelho. Revista Brasileira de Epidemiologia, Brasília, v. 6, n. 4, p. 388-404, 2003.

RIGOTTO, R. M.; AUGUSTO, L. G. S. Saúde e ambiente no Brasil: desenvolvimento, território e iniqüidade social. Cadernos de Saúde Pública, Rio de Janeiro, v. 23, supl. 4, p. s475-s501, 2007.

SANTOS, A. P. L. Tecendo redes, superando desafios: estudo dos processos de trabalho de casos exitosos em Saúde do Trabalhador no Sistema Único de Saúde do Estado de São Paulo. 2010. 265 f. Tese (Doutorado em Saúde Coletiva)-Departamento de Medicina Preventiva, Universidade Federal de São Paulo, São Paulo, 2010.

SANTOS, A. P. L.; LACAZ, F. A. C. A Saúde do Trabalhador no SUS: contexto, estratégias e desafios. In: MINAYO-GOMEZ, C.; MACHADO, J. M. H.; PENA,
P. (Org.). Saúde do trabalhador na sociedade brasileira contemporânea. Rio de Janeiro: Abrasco, 2011. p. 87-106.

SÃO PAULO (Estado). Secretaria de Estado de Saúde. Lei nº 10.083, de 13 de setembro de 1998. Institui o Código Sanitário Estadual. In: MINISTÉRIO DA SAÚDE. Caderno de Legislação em Saúde do Trabalhador. 2. ed. Brasília: Ministério da Saúde, 2005. Secretaria de Estado de Saúde. Coordenadoria de Controle de Doenças. Portaria CVS n. 2, de 28 de março de 2007. Dispõe sobre a necessidade de avaliar e gerenciar fatores de risco à saúde humana relacionados ao consumo humano de água de mananciais subterrâneos, utilizada cono solução alternativa coletiva de abastecimento. Disponível em: $<$ http://www.cvs.saude.sp.gov.br/pdf/07pcvs2.pdf $>$. Acesso em: 1 jun. 2010.

. Secretaria de Estado de Meio Ambiente. Resolução nº 5, de 28 de março de 2001. Dispõe sobre a aplicação e o licenciamento ambiental fontes de poluição. Disponível em: <www.cetesb.sp.gov.br/ Servicos/licenciamento/postos/legislacao/Resolucao_ Sma_05_01.pdf $>$. Acesso em: 19 abr. 2010.

SATO, L.; LACAZ, F. A. C.; BERNARDO, M. H. Psychology and workers' health movement in the state of São Paulo. Journal of Health Psychology, London, v. 9, n. 1, p. 121-130, 2004.

SECRETARIA MUNICIPAL DE SAÚDE. Ficha de Acolhimento em Saúde do Trabalhador para Exposição a riscos químicos "Projeto de Vigilância em PRCV/PA. Campinas, 2009a. Mimeo.

. Roteiro de Vistoria de Ambientes e Processo de Trabalho de Postos de Revenda de Combustíveis a Varejo e Postos de Abastecimento- PRCV/PA. Campinas, 2009b. Mimeo.

. Centro de Referência em Saúde do Trabalhador. Termo de Referência do Projeto de Vigilância em Postos de Revenda de Combustíveis a Varejo e Postos de Abastecimento- PRCV/PA. Campinas, 2009c. Mimeo.

SPEDO, S. M. Saúde do trabalhador no Brasil: análise do modelo de atenção proposto para o Sistema Único de Saúde (SUS). 1998. 177 f. Dissertação (Mestrado em Saúde Coletiva)-Faculdade de Ciências Médicas, Unicamp, Campinas, 1998.

TAMBELLINI, A. T.; CAMARA, V. M. A temática saúde e ambiente no processo de desenvolvimento do campo da Saúde Coletiva: aspectos históricos, conceituais e metodológicos. Ciência e Saúde Coletiva, Rio de Janeiro, v. 3, n. 2, p. 47-59, 1998.

VASCONCELLOS, L. C. F. Saúde, trabalho e desenvolvimento sustentável: apontamentos para uma Política de Estado. 2007. 421 f. Tese (Doutorado em Saúde do Trabalhador e Ecologia Humana)-Centro de Estudos da Saúde doTrabalhador e Ecologia Humana, ENSP, Fiocruz, Rio de Janeiro, 2007.

YIN, R. K. Estudo de caso: planejamento e métodos. Porto Alegre: Bookman, 2001. 